\title{
Control and Hardware Implementation of Wireless Surveillance Robot Using Solar Power
}

\author{
Jayalakshmi N. S. , R. Shivarudraswamy, Sunil Poddar and Kalyani S. \\ Department of Electrical and Electronics Engineering, Manipal Institute of \\ Technology, Manipal Academy of Higher Education, Manipal-576104, \\ Karnataka, India -576104 \\ jayalakshmi.ns@manipal.edu
}

\begin{abstract}
Solar energy is a green energy that has eased the mankind's dependency on nonrenewable sources of energy. This paper is based on the concept of utilizing solar energy to power a wirelessly controlled four-wheeled surveillance robot. Firstly, a solar charge controller is designed and then a wireless controller for the robot is designed. The output of charge controller is given to electrical drive circuit of the robot. In today's world of uncertainty, surveillance and security are of prime importance. The hardware is implemented for the same and integrated with a surveillance camera. This paper aims to control and design a robot that can be used to monitor defense activities or can be used to explore the unidentified territories that can pose a threat to any physical entity. It can also be used for general security purposes.
\end{abstract}

Keywords: Solar powered robot, charge controller, wireless DC motor control, Surveillance Robot

\section{Introduction}

In present days, due to the fast rate of depletion of conventional sources of energy, electric drives have gained popularity for the control of hybrid vehicles. They are not just pollution free but power can also be precisely controlled. They pose great difficulties when it comes to the recharging of the batteries and so they are not a standalone system. However, if we use solar energy for charging of batteries and to supply the electric drives, when needed, the system becomes more efficient and a standalone system. Photovoltaic cells can be used for this purpose as it converts sunlight directly into DC electricity. Since solar energy is also a green energy the overall system is pollution free and completely a standalone system.

Surveillance technology is an important area of research nowadays. Surveillance usually involves deploying of human personnel directly in or around areas where constant monitoring is required. There is always a risk of losing personnel in an event of being caught by an enemy or when an unidentified territory is being explored which can pose a threat to any physical entity. However, with the advancement in technology it is possible to deploy a robot in such areas instead of humans. The robot can rather be wirelessly controlled by a human who can be way out of harm's way. By equipping them with cameras and sensors, they can provide live feedback to the human operator and the operator can command the robot to take actions accordingly.

Many research papers explain the navigation and control system for robot using Arduino microcontroller [1-3]. Cameras have been used for live video feedbacks [1-2]. Autonomous robots have been also developed for surveillance purpose [2]. Wireless

Received (August 15, 2017), Review Result (October 17, 2017), Accepted (March 27, 2018)

* Corresponding Author 
communication for control of DC Motor has been achieved using Bluetooth [3]. Wireless remote controller has been used for a solar powered robot for agriculture but the range is limited. Researchers have worked on maximum power point tracking (MPPT) techniques for solar powered robotic vehicle [5]. Theoretical models of solar hybrid cars have also been developed in [6].

The modeling of solar charger and charging unit of solar powered vehicle is discussed in [7-8]. Mobility and control of electrical vehicles has been discussed in [9-10]. A smallscale transmission, generation and distribution system can be made and used for various applications as explained in [11]. In [12], the modeling of low power high charge density solar charge controller is described. The modeling of solar vehicle and improving the drive range is explained in [13-15].

This paper aims at designing a wireless, solar powered four-wheeled surveillance robot that can give live video feedback. Operating panel for controlling the direction and speed of the robot is designed using LabVIEW and the wireless communication is achieved using X-bee. Arduino microcontroller along driver circuit is used to control the DC motors. They are powered using the solar power or battery depending on the amount of sunlight falling on the PV panel by using charge controller. The charge controller is designed so that battery operates the motors if the PV output current is less than $1 \mathrm{~A}$. The LabVIEW program controls the robot accurately up to a radius of 100 meters and is limited by the communication range of X-Bees used. X-bees that are more powerful can give a better range but cost would increase.

\section{System Configuration}

Figure 1 shows the schematic block diagram of the system and it consists of an operating panel and a robot. The wireless communication is established using two X-bee modules. The transmission range of X-bee is $100 \mathrm{~m}$. Its bandwidth is $250 \mathrm{kbps}$ maximum and network size is $2^{6}$. The control panel is designed using LabVIEW. The LabVIEW program controls the robot accurately up to a radius of 100 meters and is limited by the communication range of $\mathrm{X}$-Bees used. $\mathrm{X}$-bees that are more powerful can give a better range but cost would increase.

The user sends the control signals to the robot to vary the speed and direction using this control panel. Arduino sends signals to the L298 Motor Driver Board to drive the motors accordingly. Camera of the android smart phone placed on the robot acts as the eye of the operator by sending live video streaming feedback. To power the Arduino and the motor driver a DC voltage is required. A $12 \mathrm{~V}$ solar panel and battery with charge regulator has been designed for this purpose. It takes the feedback from the voltage dividers and current sensors, which are a part of the charge regulator circuit, and follows control algorithm to decide the amount of current flowing through solar and battery. It thus decides whether the system is in solar mode, battery mode or hybrid mode. 


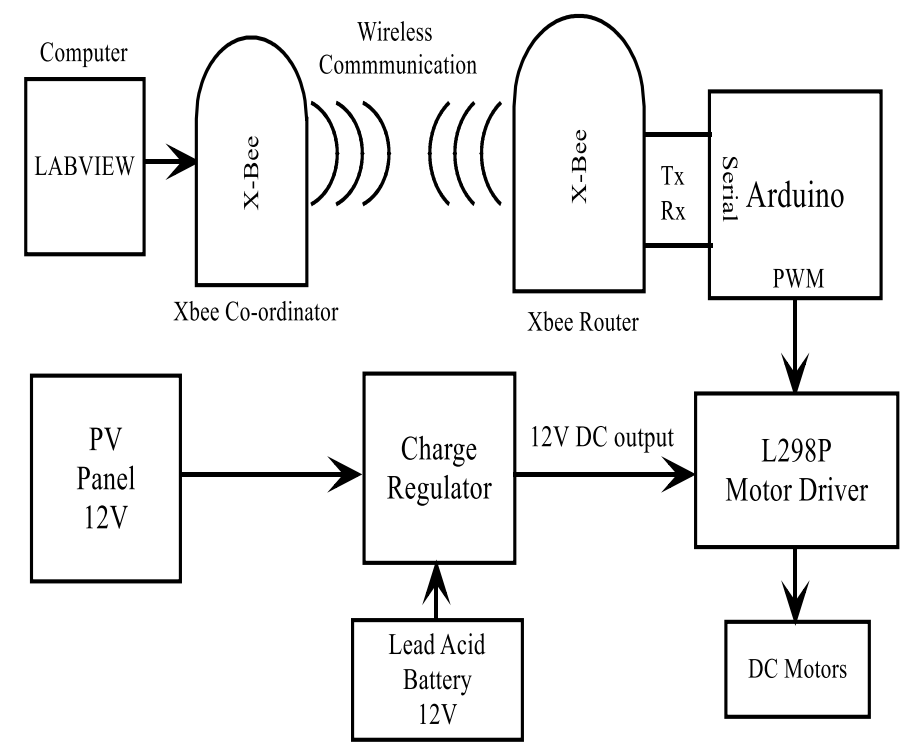

Figure 1. Schematic Diagram of the System

\section{Control System}

The control system of solar powered wireless four-wheeled surveillance robot is divided into three different sections. They are solar charge regular, DC Motor Control and live streaming incorporated using camera of an Android phone as explained in the following sections. The LabVIEW program controls the robot accurately up to a radius of 100 meters and is limited by the communication range of X-Bees used.

\subsection{Solar Charge Regulator}

The charge regulator is controlled by an Arduino depending on the voltage of battery, voltage and current from the solar panel and current required by the load. Voltage divider circuits are used to measure the voltage of solar panel and battery. The current sensors ACS712 are used to measure current through solar panel and the load current.

The duty cycle of the PWM signal of p-MOSFET driver on solar panel is adjusted accordingly. Fixed frequency PWM technique is used and frequency $490 \mathrm{~Hz}$ is given to the solar panel side p-MOSFET. The duty cycle is adjusted according to the algorithm depicted in Figure 2. On the load side the triggering signal only toggles between on and off, to turn on and turn off the load accordingly.

Bulk charging stage of the battery is where the highest voltage rating of battery charger can be used without over heating the battery. Typically, the charging voltage is $14.6 \mathrm{~V}$ $14.8 \mathrm{~V}$ for a $12 \mathrm{~V}$ battery. During the float stage of charging the charging voltage tapers down to $13.2 \mathrm{~V}-13.4 \mathrm{~V}$ in order to maintain $100 \%$ state of charge. Bulk charge voltage is set to be $14.6 \mathrm{~V}$ and float charge voltage is set to be $13.2 \mathrm{~V}$. The charging takes place when voltage of solar panel is higher than battery voltage. When battery voltage is less than float charge voltage or when battery voltage is between float charge voltage and bulk charge voltage but the load current is higher than the current provided by solar panel, duty cycle is made $100 \%$. 


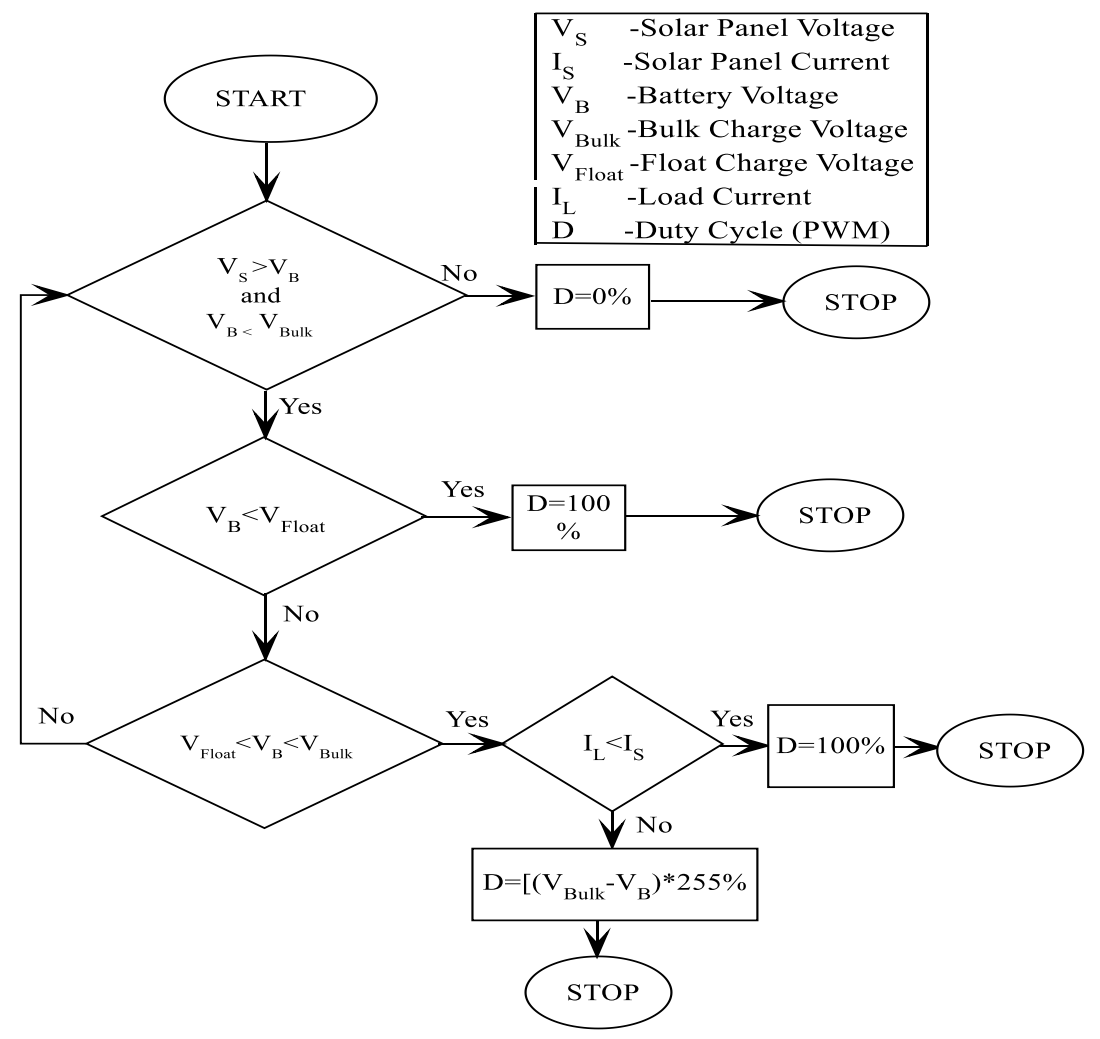

Figure 2. Charging Algorithm

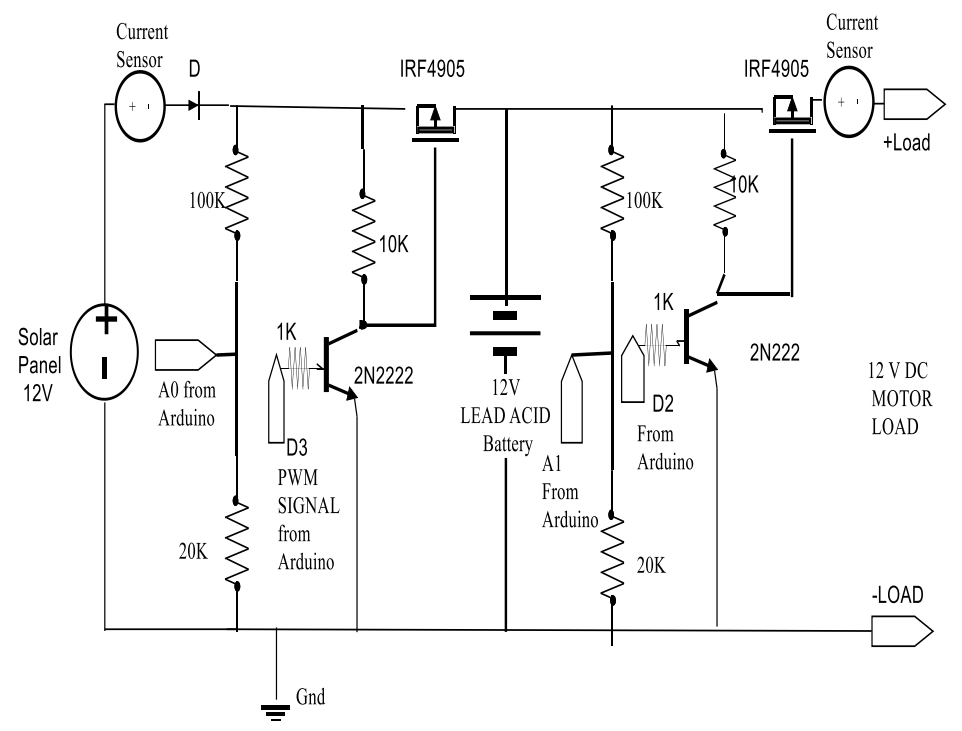

Figure 3. Charge Regulator with Sensors to Measure Voltages and Currents

The p-MOSFET driver acts as a switch. When the NPN transistor is non-conductive, $12 \mathrm{~V}$ voltage appears across the gate of the p-MOSFET. As long as voltage across both gate and source is at $12 \mathrm{~V}$, the p-MOSFET remains turned off. When $5 \mathrm{~V}$ is applied to the base of the NPN transistor, the transistor turns on and voltage across collector becomes $0 \mathrm{~V}(0.5 \mathrm{~V}$ practically). To turn on the p-MOSFET, the gate should be negative with respect to the source. Therefore, in this condition, the gate voltage is $0 \mathrm{~V}$ and the source voltage is $12 \mathrm{~V}$, hence the gate voltage is less negative as compared to source voltage and 
hence the MOSFET turns on. Figure 3 shows schematic diagram of charge regulator with sensors to measure voltages and currents.

\subsection{Motor Control}

The operator can control the movement and speed of the robot using LabVIEW control panel as shown in Figure 4. The X-bee attached to laptop sends the commands to the Xbee connected to Arduino. According to the command sent, the Arduino controls the enable and input pins on the motor driver L298P. The L298P is a two channel motor driver and can drive two DC motors, one from each channel. Each channel on the L298P individually delivers up to $2 \mathrm{~A}$ to the motors connect. There are two types of input in L298P that is direction and enable. The direction inputs are either high or low. The enable pins of L298P pins are controlled using PWM signals according to which speed of the robot can be changed. Figure 5 (a) details the block diagram for DC motor control and Figure 5 (b) shows the pin diagram of L298P. The motor parameters are shown in Table 1.

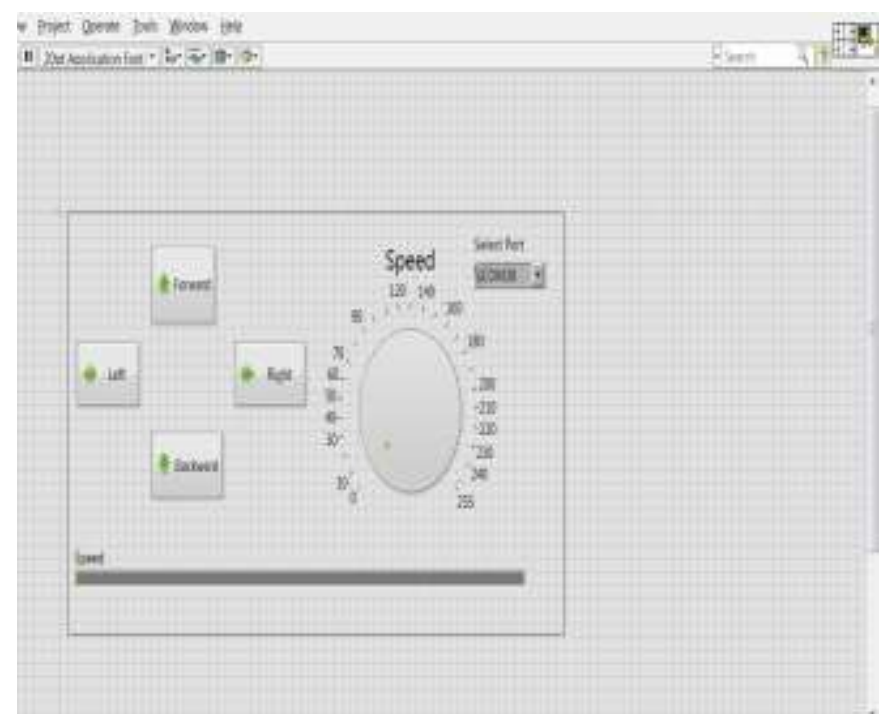

Figure 4. LabVIEW Front Panel to Give Commands to Robot

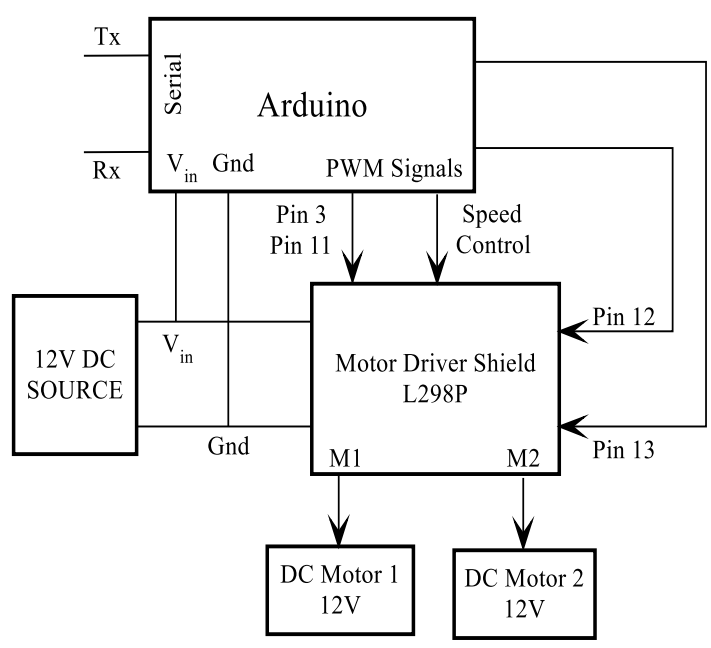

(a)

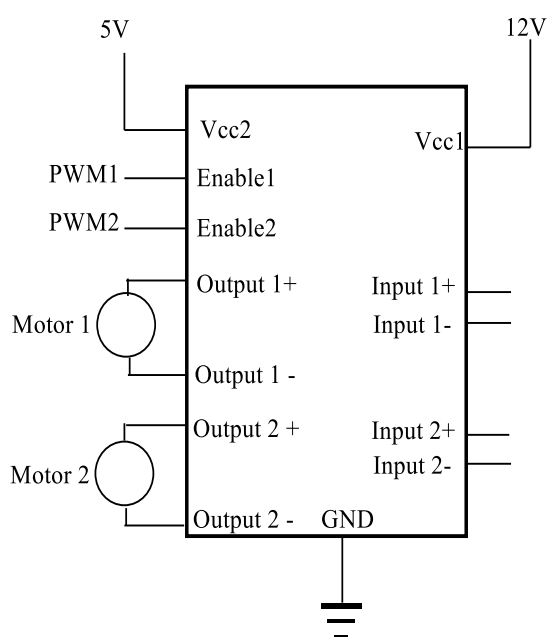

(b)

Figure 5. (a) Block Diagram for DC Motor Control (b) Pin Diagram of L298P 
Table 1. The Parameters for the Selected Motor

\begin{tabular}{|l|l|c|}
\hline \multicolumn{1}{|c|}{ Variable } & Values & Units \\
\hline Mass (Estimated) & 5 & $\mathrm{Kg}$ \\
\hline Velocity (Desired) & 0.14 & $\mathrm{~m} / \mathrm{s}$ \\
\hline Acceleration (Desired) & 0.14 & $\mathrm{~m} / \mathrm{s}^{2}$ \\
\hline Efficiency (Estimated) & 75 & $\%$ \\
\hline Angle of incline & 0 & $\mathrm{degrees}$ \\
\hline Constant of gravity & 9.81 & $\mathrm{~m} / \mathrm{s}^{2}$ \\
\hline Number of powered wheels (n) & 4 & \\
\hline Diameter of wheel & 0.1 & $\mathrm{~m}$ \\
\hline
\end{tabular}

Motor Selection: The motor revolution per second is given by the following relation,

Motor RPS $=$ Velocity $\times \pi \times$ Diameter of wheel $=0.477 \mathrm{rps}$

Torque $\times$ Revolution per second $>=\frac{\text { MassXAccelerationXVelocity }}{2 \pi}$

The robot motor selection factor (RMSF) is represented by

$$
\text { RMSF }=\frac{\text { Mass XAcceleration } \times \text { Velocity } \times \text { Number of powered wheels }}{2 \pi \times \text { Efficiency }}
$$

$$
\begin{aligned}
& =\frac{5 \times 0.14 \times 0.14 \times 4}{2 \pi \times 0.75} \\
& =0.08318 \mathrm{Kg}-\mathrm{m}-\mathrm{rps}
\end{aligned}
$$

The motor selected has Torque $0.02 \mathrm{Kg}-\mathrm{m}$ and Speed $300 \mathrm{rpm}$ and RMSF $=0.1 \mathrm{Kg}-\mathrm{m}$ rps. It is seen that the motor selected has greater RMSF than required by the system.

\subsection{Configuration of Spy-Cam}

Presently spy-cam for live streaming is incorporated using camera of an Android phone. For this application called IP webcam [18] is used as shown in Figure 6. Presently it is independent of the system and runs through Wi-Fi network. In future, wireless video streaming using $\mathrm{X}$-bee modules will be incorporated. Live streaming is required for surveillance purpose as this will act as the eye of the operator as the operator can easily see and scan the area. This can be integrated with audio feedback in future to provide an even better feedback for surveillance.

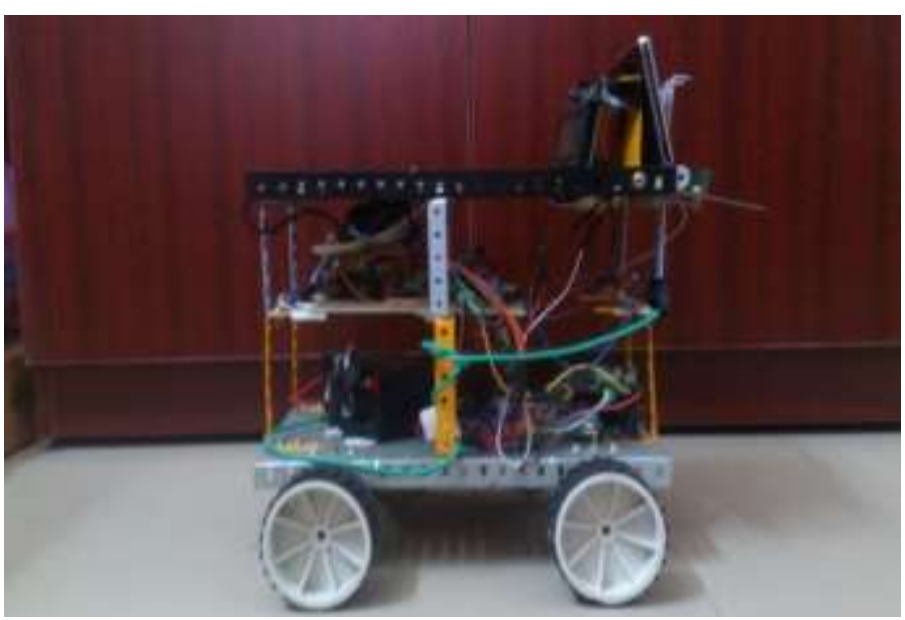

Figure 6. Live Video Streaming 


\section{Hardware Implementation}

The 12V DC output of the solar charge regulator is used to power up the Motor Driver L298P and Arduino. When user sends commands to the robot or when the robot is moving through a terrain the current required to run the DC motor change accordingly. This change is sensed by the current sensor present in the load side of charge regulator as shown Figure 3 and it acts accordingly. The spy-cam is an independent unit and it is mounted on top of the robot. The operator can see the live video streaming and give the commands to the robot accordingly. The LabVIEW program controls the robot accurately up to a radius of 100 meters.

When the robot is in stationary state, that is, when the speed is zero, no current is drawn by it. Therefore, during a sunny day and at zero speed, the battery will be charged and no current will be given to the load. When the speed gradually increases, the current sensor attached to it will sense the load current. The PV cell will try to supply the load. As the load varies, the charge regulator will decide whether the DC motors are powered using solar panel or battery

The robot has three levels. As depicted in Figure 8 and Figure 9, the lower level contains the battery, motors and motor driver and the middle level contains the charge controller circuit. The top level has a solar panel as shown in Figure 7 and an Android smart phone as shown in Figure 9.

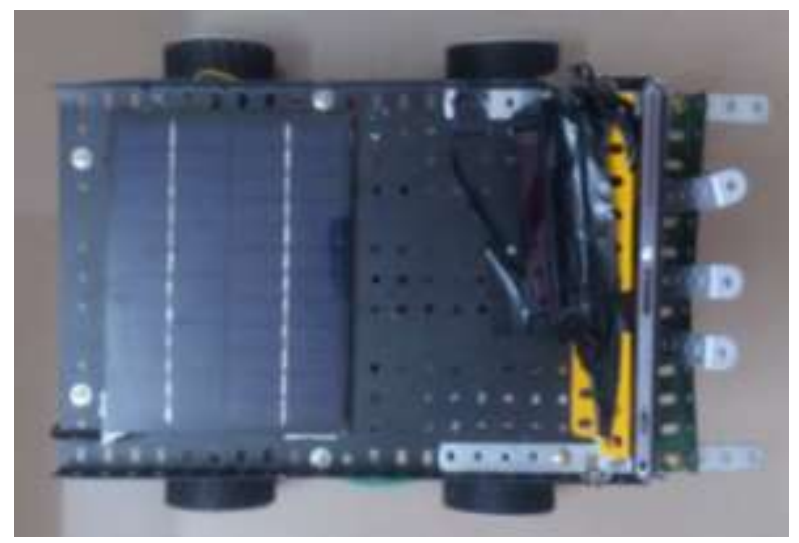

Figure 7. Top View of Solar Powered Robot

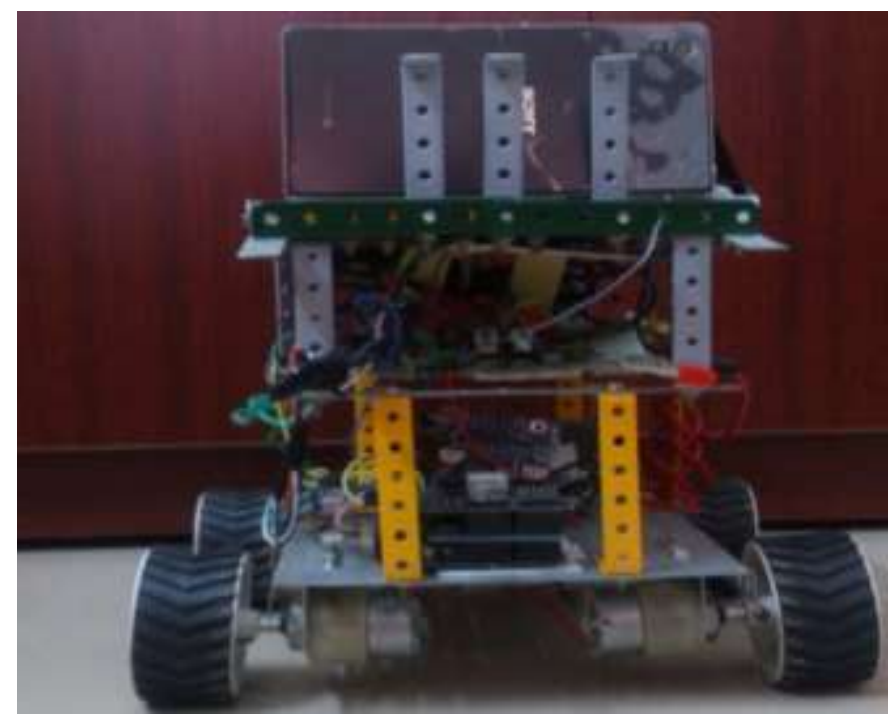

Figure 8. Side View of Robot 


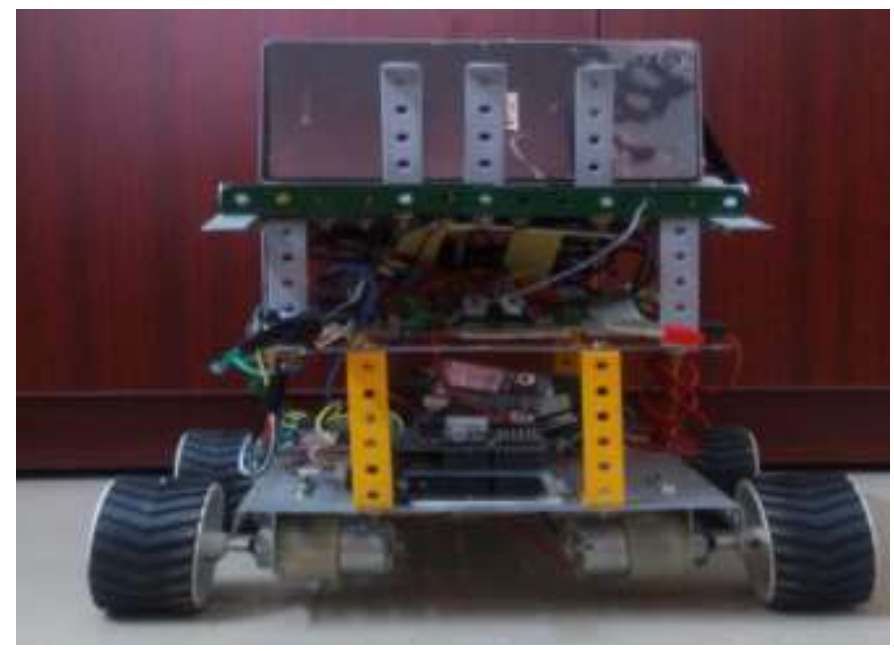

Figure 9. Front View of Robot

\section{Conclusion}

A charge regulator is modelled and is tested with a DC load. The hardware implementation of wireless speed control of DC motor is realized using LabVIEW, Xbees, Arduino and motor driver L298P. The charge regulator chooses the DC supply from solar panel or battery for the motor driver and Arduino. If the solar energy is available robot vehicle will work only on solar power, otherwise battery will supply the required power for the robot operation. A spy-cam gives the live video feedback for surveillance purpose. With the help of live streaming, the movement and surrounding environment of the robot can be easily seen. In the present range, the robot can easily attain speed up to $3 \mathrm{~m} / \mathrm{s}$ when the speed is set to full using LabView. Because of the charging algorithm used, the robot is a self-sufficient system and charges the battery itself when in idle condition.

\section{References}

[1] C. Kulkarni, S. Grama, P. Gubbi Suresh, C. Krishna and J. Antony, "Surveillance Robot Using Arduino Microcontroller, Android APIs and the Internet", First International Conference on Systems Informatics, Modelling and Simulation, (2014).

[2] H.-T. Lee, W.-C. Lin, C.-H. Huang and Y.-J. Huang, "Wireless indoor surveillance robot", SICE Annual Conference, (2011).

[3] A. Khanna and P. Ranjan, "Solar -Powered Android-Based Speed Control of DC Motor via Secure Bluetooth", Fifth International Conference on Communication Systems and Network Technologies, (2015).

[4] P. Jothimurugan, J. Muthu Saravanan, R. Sushanth, V. Suresh, H. Siva Subramaniam, S. Vasantharaj and S. Yogeswaran, "Solar E-Bot for Agriculture", Texas Instruments India Educators' Conference, (2013).

[5] S. S. Warekarl and B. T. Salokhe, "Solar powered robotic vehicle", International Journal of Advanced Research in Computer and Communication Engineering, vol. 4, no. 5, (2015) May.

[6] D. Barrit and Y. Salih-Alj, "Ralos Car: Solar Powered Car with a Hybrid Backup System", IEEE Symposium on Industrial Electronics and Applications (ISIEA2012), Bandung, Indonesia, (2012) September 23-26.

[7] R. Arulbel Benela and K. Jamuna, "Design of charging unit for electric vehicles using solar power", Information Communication and Embedded Systems (ICICES), 2013, International Conference on Chennai, (2013), pp. 919-924.

[8] M. Mohanraj, R. Thottungal and S. Johnson, "Dynamic solar powered robot using dc-dc sepic topology", IJRET: International Journal of Research in Engineering and Technology, vol. 03, no. 02, (2014) February.

[9] J. H. Lever, A. Streeter and L. R. Ray, "Performance of a solar-powered robot for polar instrument networks", Proceedings 2006 IEEE International Conference on Robotics and Automation, 2006. ICRA 2006, Orlando, FL, (2006), pp. 4252-4257. 
[10] J. V. Vas, S. Venugopal and V. G. Nair, "Control scheme for electrical drive of solar powered vehicles", 2008 Annual IEEE India Conference, Kanpur, (2008), pp. 75-80.

[11] Y.-P. Lee, E.-C. Liu and H.-Y. Huang, "A small scale solar power generation, distribution, storage, MPPT and completed system design method", Communications, Circuits and Systems (ICCCAS), 2010 International Conference on Chengdu, (2010), pp. 597-600.

[12] M. Islam and M. A. B. Sarkar, "An efficient smart solar charge controller for standalone energy systems", Electrical Drives and Power Electronics (EDPE), 2015 International Conference on, Tatranska Lomnica, (2015), pp. 246-251.

[13] V. A. Katic, B. Dumnic, Z. Corba and D. Milicevic, "Electrification of the vehicle propulsion system an overview", FACTA UNIVERSITATIS Series: Electronics and Energetics, vol. 27, no 2, (2014) June, pp. 299-316.

[14] N. Shaha and Md. Bashir Uddin, "Hybrid Energy Modeling for Auto Vehicles", Paper ID: ET27.Available:http://icmimeruet.ac.bd/2013/Contents/Technical\%20Papers/Energy\%20Technology/ET27.pdf.

[15] M. Azlan Hussin, A. N. Abdalla, R. Ishak, R. Abdullah and Z. Mohd Ali, "Study on improving electric vehicle drive range using solar energy", Electrical, Control and Computer Engineering (INECCE), 2011 International Conference on Pahang, (2011), pp. 373-376.

[16] Smart Phone for live video streaming. In the MATLAB forums [Online]. Available: http://www.mathworks.in/matlabcentral/answers/12036, (2013) February.

[17] IP Webcam application, Google Play [Online] Available:https://play.google.com/store/apps/details? id=com.pas.webcam\&hl=en, (2012) February.

[18] Sealed Lead Acid battery datasheet, 12V [Online] Available: http://docseurope.electrocomponents.com/webdocs/0b5b/0900766b80b5b643.pdf.

[19] Current Sensor ACS712 datasheet [Online]. Available:http://pdf1.alldatasheet.com/datasheet$\mathrm{pdf} / \mathrm{view} / 168326 / A L L E G R O / A C S 712 . \mathrm{html}$.

[20] Temperature Sensor LM35 datasheet [Online]. Available: http://www.ti.com/lit/ds/symlink/lm35.pdf. 
International Journal of Control and Automation

Vol. 11, No. 5 (2018) 